\title{
MÚSICA Y POESÍA: EL MITO DE ORFEO EN LA POÉTICA DEL RENACIMIENTO ESPAÑOL
}

\author{
In memoriam: Alberto Porqueras Mayo
}

Enrique Valdés*

Orfeo es considerado el primer poeta, músico y teólogo del mundo antiguo. ${ }^{1}$ En cuanto a su origen existen algunas discrepancias, pues en las mitologías se dice que Orfeo fue hijo de Eagro, rey de Tracia. Para los españoles, en cambio, persiste la versión más poética, que lo considera hijo de Apolo, Dios de la música, y de Calíope, musa de la poesía. Orfeo nació en Tracia, un siglo antes de la guerra de Troya. Ama la música tanto como su propia voz. Y posee un escudo que por uno de sus lados protege del amor y por el otro lo esparce y perpetúa. Es famoso su desdén por las mujeres de Tracia, frente a las que Orfeo aparece impasible, hasta el día en que conoce a Eurídice, cuyo nombre significa luz o aurora. ${ }^{2}$ Orfeo se enamora y se casa con la bella Eurídice, pero ella muere por la mordedura de una serpiente, mientras huía del lascivo Aristeo. Para Ovidio, Eurídice habría muerto por la mordedura de una serpiente cuando marchaba acompañada de otras ninfas. Debido a la muerte de su amada, Orfeo decide bajar a los infiernos y llegar hasta Plutón para buscarla. Armado de su lira, atraviesa la cueva de Ténaro y el Leteo o "río del olvido". Se embarca en la mísera barca de Caronte para llegar hasta las puertas de Cerbero, el perro de tres cabezas que intenta detenerlo; pero el dulce canto de su instrumento adormece al can y Orfeo entra al mundo de las tinieblas para exponer su único argumento: el amor y la fidelidad a la mujer que ama. El poder de su lira y de su canto, así como la naturaleza de su dolor - el mismo por el que Plutón había raptado a su mujer Proserpina - paralizan las crueldades del infierno. Tántalo no coge el agua que siempre se le escapa; la rueda de Sísifo se ha detenido. Orfeo recibe a Eurídice con la condición de que no podrá mirarla hasta que hayan salido a la luz. Pero la curiosidad y el excesivo amor abren paso a la segunda muerte de Eurídice y a la índole desgraciada del poeta y músico. Eurídice desaparece

\footnotetext{
${ }^{1}$ Hacia el siglo VI A. C. Orfeo gozaba de una fama múltiple. Como teólogo, formaría la secta de los órficos que aplacaban las fieras y cuyos libros habría escrito el mismo Orfeo. Cfr. Pablo Cabañas. El mito de Orfeo en la Literatura Española, 1948:15.

2 Juan de Jáuregui, en su "Orfeo" escribe a propósito de Eurídice: "cielos cifra su rostro: su cabeza/vierte sobre los ombros pluvias de oro". El "Orfeo” de Jáuregui se publicó, según Cabañas, en la Cythara de Apolo. Hay una edición de Cabañas en la Biblioteca de Antiguos Libros Hispánicos, A XII.
} 


\section{Enrique Valdés}

nuevamente y, aunque Orfeo vuelve a buscarla, ya no tendrá el poder sobre los dioses, a los que ha decepcionado. Ya no sirven ni su lira ni su canto. ${ }^{3}$ Orfeo se va a los montes y llora durante siete meses en las montañas de Strymon, según la descripción de Juan Boscán en su poema Hero y Leandro, inspirado en las Geórgicas de Virgilio

Los tigres y leones amansaba

y llevaba tras sí los fuertes robles

No existe tampoco una única versión acerca de la muerte de Orfeo. Para unos habría muerto fulminado por un rayo de Júpiter, por haber revelado misterios divinos a los hombres. Otra versión sostiene que, al no poder soportar la ausencia de Eurídice, se habría suicidado. La tesis más aceptada en nuestros días es la que sostiene que Orfeo fue muerto por las Bacantes de Tracia, no como una venganza divina, sino por haber rechazado sus proposiciones amorosas manteniendo su fidelidad a Eurídice. Tal es el argumento de Virgilio en las Geórgicas IV:520-523 (Cabañas 1948:33). La misma muerte está descrita en el Orfeo en lengua castellana de Montalbán y el ya citado "Orfeo" de Jáuregui, considerados los primeros textos sobre este mito en idioma castellano (Cabañas, 1948:33).

La muerte de un hombre que dignificaba el amor humano y tan divinamente dotado para la música y la palabra, no podía quedar sin castigo. El dios Baco --para quien Orfeo era uno de sus predilectos- convirtió en árboles a las mujeres que intervinieron en su muerte. Se dice que la lira de Orfeo subió al cielo y formó una constelación luminosa de estrellas. ${ }^{4}$

Muchos de los aspectos temáticos del mito de Orfeo han permanecido intactos en la literatura española mientras que otros han sido elaborados y desarrollados permanentemente. No sólo la estrecha relación que el mito establece entre música y poesía, palabra y sonido hermanados desde siempre, sino que los temas de la fidelidad, la curiosidad y la desgracia aparecen también como constantes del tema órfico. El tema de la fidelidad aparece profusamente tratado en textos del renacimiento español: en El infierno de los enamorados del Marqués de Santillana, en la Égloga III de Garcilaso; en la tragedia de Lope de Vega El marido más firme; en el ya citado Orfeo de Juan de Jáuregui y en una comedia de Antonio de Solís titulada Eurídice y Orfeo.

Nos interesa examinar ahora la presencia del mito de Orfeo en la teoría

\footnotetext{
${ }^{3}$ Esta es la descripción de Jáuregui: "i rudos forma acentos a la lira, no obedeciendo en el turbado llanto/la cuerda al plectro, ni la voz al canto", en Cabañas (1948:29).

${ }^{4}$ El tema está en la obra de Jáuregui: “....a mayor altura/la lira insigne, que en impulso leve/al cielo honró, creció la lumbre pura/del orbe octavo con estrellas nueve”, en Cabañas (1948:34).
} 
poética del Renacimiento y del Siglo de Oro en España tomando como fuente de información el libro La teoría poética en el Renacimiento y manierismo españoles (1986) de Alberto Porqueras Mayo. Como bien se señala en la Introducción de este libro, los discursos de las Academias Literarias del siglo XVI constituyen fuentes importantes de reflexiones acerca de la poesía y la estrecha alianza entre música y palabra. Así se refiere Gaspar de Aguilar a esta relación

...Porque el soberano don de la poesía es propiamente una música de palabras cuyo acento hiere el alma... (1986:46). ${ }^{5}$

La relación entre poesía y música así como el carácter sagrado de ambas es una característica que al Renacimiento le interesa resaltar. En la exaltada alocución referida, el autor atribuye oficio de poeta a Jesucristo no sólo por ser piitis, hacedor, sino porque "cuyas obras y palabras fueron lección y enseñanza; dijo versos (que esto quiere decir himnos), poco antes de su Pasión" (1986:47). Sánchez de Viana, otro teórico y poeta renacentista, apunta directamente a la integración de las artes

...los hombres sin el poético espíritu no aprenden alguna de las humanas artes... mas los verdaderos poetas, cuales afirma haber sido Orfeo, Homero, Hesíodo y Píndaro, ponen en su poesía ciertos indicios de todas las artes que son prueba de que las entendían (1986:141).

No se puede dejar de citar la referencia de Sánchez de Viana al "Fedro" de Platón y a "Filón" en el Libro de Los gigantes para expresar la idea de que sólo el alma de los sabios, a través de la música y la poesía podrá recobrar la divinidad perdida en la atadura corporal que nos une a la tierra

Ansí que sabiduría humana es retrato de la divina y la música de nuestros instrumentos figura de la celestial armonía (1986:142).

Esta armonía del cielo, a la que se hace referencia constante en la literatura del Siglo de Oro consiste, por un lado, en el orden impecable regido por la mente de Dios y, por el otro, en el movimiento y orden eterno de los astros y de las esferas que componen el concierto admirable de nuestro universo cósmico. "Destas dos especies de música gozaba el alma antes que bajase a vestirse de mortal librea" (1986:142).

La lucha de Orfeo o la que emprende Fray Luis es similar. Esperanza de "recobrar las alas para tornarse a su patria y gozar de la divina música".

${ }^{5}$ Gaspar de Aguilar. "Discurso en alabanza de la poesía, aplicada al nacimiento", en Alberto Porqueras-Mayo. La teoría poética en el Renacimiento y manierismo españoles. Barcelona: Puvill Libros S.A., 1986:46. Citaremos por esta edición. 


\section{Enrique Valdés}

Con razón Platón — tan mal interpretado por desterrar a los poetas de La República-- llamaba a los poetas intérpretes de los dioses y en "El Cratilo", pide para ellos que sean los poetas los que den a las cosas innombradas sus nombres adecuados.

Podríamos decir que en el pensamiento de San Agustín culmina la valoración de la poesía como arte civilizador. Para él, el origen de la poesía se funde con el de la música. "Los orbes mismos celebran al Criador cantando" (1986:63). En este mismo sentido creemos necesario revisar algunas alusiones entre música-poesía y teología, siguiendo la primitiva nominación de Orfeo como el primer teólogo. Al hablar de poesía y teología —dice Curtius (1955-309)—que "el más importante poeta del cenácolo padovano fue Albertino Mussato (12611329)". Mussato, hombre de Estado, historiador y poeta, escribió epístolas acerca del origen y dignidad de la poesía como una ciencia de derecho divino. Mussato dice que la poesía es una segunda teología. Moisés, Job, David y Salomón fueron poetas, hablaban en parábolas como Cristo, usaban un lenguaje de imágenes y metáforas que es el lenguaje de la poesía. Muchos teóricos se oponen a la idea del origen divino de la poesía para afirmar que, tal como las otras ciencias, es invento del hombre. Así como la ciencia pudo ser escrita en versos, también la Biblia usa su lenguaje metafórico para revelar la verdad divina, accesible sólo a los espíritus dignos de ella. La finalidad de la metáfora en la poesía tiene la función de decir lo inefable del pensamiento, mediante el símil, la comparación o la imagen. Estos son los fundamentos con que el domínico Giovanino de Mantua refuta la teoría de Mussato. Su argumento concluye citando a Orfeo, Museo y Lino - considerados los tres poetas más antiguos del mundo- sin embargo, posteriores a Moisés, con lo que la teología sería más antigua que la poesía. Curtius añade

Lo que el dominico se propone no es atacar a la poesía, sino incorporarla al sistema de ciencias sólidamente establecido por Santo Tomás (1955:309).

Para Santo Tomás, el método de expresarse con símbolos es propio de la teología y de la poesía

La poesía se refiere a cosas que, por su falta de verdad, no están al alcance de la razón... La teología se ocupa de cosas supra-racionales, de ahí que el método simbólico sea común a ambas (1986:12).

La presencia de lo sagrado en la música y en la poesía es claramente detectable en la Biblia, especialmente en el "Libro de los Salmos". Muchos de los himnos del antiguo Israel fueron compilados desde antiguas colecciones de alabanzas líricas compuestas para acompañar la realización del culto y la 
presencia del hombre en el templo. Aunque incluyen variedad de temas como himnos, canciones de Zión, lamentos, cantos litúrgicos y de bodas, la constante musical está en todos ellos, a veces, explícitamente como en el Salmo 4: "Al maestro del Coro: con instrumentos de cuerda". O en el Salmo 5: "para flautas". En el número 45 el autor se identifica como un escritor profesional, posiblemente un poeta de la corte

Yo dirijo mis versos hacia el rey y mi lengua es como la pluma de un escriba bien dispuesto.

Uno de los tópicos que culminará en el Siglo de Oro - la promesa de la inmortalidad literaria— aparece en el versículo 17

Yo haré que tu nombre sea celebrado por todas las generaciones; por lo tanto, los pueblos te alabarán siempre

Canto y poesía, canción y plegaria, ruego y ritual conforman un inseparable sintagma de sentido, imposible de diferenciar en los salmos bíblicos. El penúltimo de ellos —número 149- es un himno destinado a acompañar la danza: "hagan melodías para él, con tambores y liras". Sabido es que el clásico instrumento de Orfeo alcanza el nivel de lo sagrado en los textos bíblicos. El Salmo 150 contiene, como un orgiástico final de una sinfonía, la descripción de los instrumentos que acompañan a la palabra y la voz que alaba a Dios

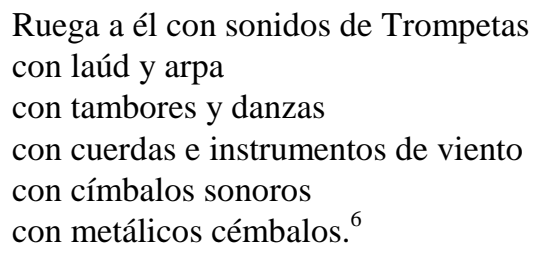

En este mismo sentido, resulta interesante destacar la referencia a la organización de los músicos y de la música que se encuentra en el "Libro de las Crónicas" 1-25;1-31, donde David organiza a los músicos. Para las 24 divisiones de ruegos y oraciones proyecta 24 divisiones de músicos. Los instrumentos nombrados son nuevamente címbalos, arpas y liras "al servicio de la casa de Dios". En las listas de nombres de David a sus grupos, aparecen algunos juegos de palabras muy adecuados a la función poética y musical de la liturgia, como gracioso, exaltado, magnífico, abundante y visionario. No escapó a los primeros preceptistas del siglo XVI, alguna observación acerca de la función nemotécnica de la música en la poesía. Así leemos en Arte poética española de Juan Díaz

\footnotetext{
${ }^{6}$ The Oxford Annotated Bible. The Holy Bible. Oxford: Oxford University Press, 1962:656-658.
} 


\section{Enrique Valdés}

\section{Rengifo (1592).}

Es la poesía buena para enseñar y mover, porque en ella se pueden decir verdades y dar avisos y consejos saludables; los cuales por ir en aquel estilo se quedan mejor en la memoria y se imprimen en los corazones y más aún cuando algún buen músico los canta (1986:157).

También Rengifo hace referencia al poder que este arte ejerce sobre los hombres, las cosas y las fieras

Efetos destos se atribuyen a los sabrosos y elegantes versos que Orfeo y Anfión cantaban

Lo que destacaba Rengifo era el poder de la música y la poesía para mover a los hombres duros y amansarlos, "quitarles la fiereza natural conque se habían criado y hacerles parar en medio del furor de sus pasiones" (1986:158). Parecida función ejercería la inclusión del canto y la música en la Iglesia y la liturgia, desde los salmos de David hasta los himnos compuestos por San Ambrosio, San Gregorio el Teólogo, y San Dámaso, "nuestro español", como él lo llama.

Las figuras de Orfeo y Anfión vuelven a aparecer en la poética española en el "Discurso..." de Lupercio Leonardo de Argensola, pronunciado en una academia de Zaragoza a fines del XVI (1986:161).

Orfeo y Anfión desta manera

hicieron leyes y pudieron tanto

reduciendo a quietud la gente fiera.

Fingió la antigüedad que con su canto

pudo el uno viajar al reino oscuro

y suspender sus furias entre tanto.

$\mathrm{Y}$ el otro con su lira en alto muro

de Tebas fabricar, yendo llamadas

las piedras sin tocarlas hierro duro (1986:161).

Incluye, además, una valiosa recomendación, vigente en nuestros días

“Lean mucho, escriban, amen el borrar mil veces cada palabra” (1986:162).

En el interesante texto de Alfonso López Pinciano, Filosofía antigua poética (1596), el autor trata de establecer la diferencia entre música y literatura

¿No veis que ésta tiene su esencia en el movimiento y aquella en el término? (1986:165).

Establece una diferencia de primera importancia en la estética contemporánea entre artes espaciales y temporales. En este mismo diálogo entre Fadrique y 
Pinciano, se cita la opinión que de la música y la poesía tenía Aristóteles en sus Políticos.

Tres provechos traen estas artes: el uno alterar y quietar las pasiones del alma a sus tiempos convenientes; el segundo, mejorar las costumbres; y el tercero, divertimiento y entretenimiento (1986:165).

También desarrolla Pinciano la asociación de la palabra "lírica" referida al género poético, con la lira, instrumento musical. La poesía mezcló el arte de la música a la suya por dos causas: para deleitar y para enseñar que son los fines de la poética. Música y poesía influyen, además, en el ánimo del ser humano potenciando sus propias condiciones naturales: "si la música coge a un hombre triste, lo hace más triste y, si alegre, mucho más le alegra" (1986:187). En este mismo diálogo, Pinciano define la relación existente entre música, poesía y danza

Me parece que andáis corto en la definición o descripción de la lírica, porque si ella queda en lugar de la ditirámbica, no sólo ha de ser para ser cantado, sino metro para ser tañido y danzado (1986:186)

Para todo aquel que tenga la experiencia de escuchar la buena música, resulta evidente que su arte, hecho de sonidos que no tienen una significación inmediata en el ámbito lingüístico, produce un placer muy diferente que el sonido de las palabras en la poesía, ya que estos últimos — aun en la poesía más hermética como la de Góngora o Mallarmé-- están constreñidos, por así decirlo, a una asociación inseparable entre significante y significado. Sonido y sentido que puede obviarse en la obra musical. A esta particularidad pareciera que alude la observación de Luis Alberto Carvallo quien, al hablar del "furor poético" de los músicos, dice que

se contentan con la armonía del oído, que hasta estos tienen este furor, igual con los poetas, sin pasar a la armonía y correspondencia de toda la materia y su sentido.

En el Compendio apologético en alabanza de la poesía de Bernardo de Balbuena (México, 1604) se establece la relación armónica entre voz, música y canto.

Por eso fue dado al mundo el coro de las musas, porque la tierra sin él no quedase inculta y bárbara (1986:272).

El mismo Balbuena cita a San Isidro para quien

tan torpe cosa es no saber música como no saber letras, pues, qué música hay sin poesía, si la poesía es el alma de la música (1986:276). 


\section{Enrique Valdés}

Finalmente, para señalar la presencia de Orfeo en Fray Luis, nos será muy útil la anotación que Balbuena hace de Lucencio respecto a su referencia a la teoría de la armonía celestial, que tomará posteriormente Fray Luis en su famosa "Oda a Salinas". Dice Balbuena que, "el universal criador del mundo"

Compuso los cielos todos

Dios en números cabales,

y mandándoles por ser tales

resonar en dulces modos

y tejer danzas iguales (1986:276).

Para esta concepción, conocida como Pitagórica, el universo tiene siete orbes "que se vuelven y voltean en suavísima armonía y consonancia". La imagen de un cielo colmado de ángeles que cantan y alaban a Dios por medio de la música y de la palabra se ha extendido hasta nuestros días, porque

desde el principio de la creación crió Dios su capilla de músicos y poetas celestiales (1986:276).

Las reiteradas menciones al mito de Orfeo en la literatura como en la música muestran la estrecha relación que existe entre música y poesía a través de la historia del arte y la cultura. Aunque la poesía es el arte que se manifiesta por la palabra, la plenitud de un poema es un complejo en que la función sonora del lenguaje tanto como la relación entre significantes y significados juegan un papel importantísimo en el placer estético, aspectos que no pueden dejarse de lado en la apreciación ni en el análisis. Stravinsky, como otros músicos contemporáneos, ha reflexionado acerca de estas relaciones con el propósito, al parecer, de hacer racional la innovación que han aportado en el desarrollo de la música (1942). Lo que hasta principios del siglo XX llamábamos disonancias — como los intervalos de segunda o cuarta- nos parecen ahora tan familiares como los de tercera y quinta, que forman el acorde perfecto. Nuestros hábitos auditivos, como toda nuestra vida, no escapan a los cambios de gusto y de apreciación que provoca la evolución de las artes. ${ }^{7}$

\footnotetext{
${ }^{7}$ El mito ha sido tema de la pintura, la escultura, la literatura y, especialmente, de la música. Claudio Monteverdi (1567) consagró lo que se considera la primera ópera existente: Orfeo, favola in musica; Joseph C. Gluck (1714) escribió Orfeo y Eurídice y Jacques Offembach una opera cómica: Orfeo en el Infierno. También fue llevado al ballet por Stravinsky en 1948. En el teatro aparece desde Esquilo hasta Tennesee Williams. Las versiones más antiguas fueron las de Virgilio en Las Geórgicas y la de Ovidio en La Metamorfosis. En el cine latinoamericano cuenta con Orfeo Negro, dirigida por Marcel Camus, sobre un guión del poeta y compositor Vinicius de Moraes, Orfeu da Conceição.
} 
Una de las culminaciones de la relación música-poesía, ligadas al hermoso mito de Orfeo, es la "Oda a Salinas" de Fray Luis de León. El sacerdote ciego a quien está dedicada la Oda, pareciera un Orfeo personificado. Pero ¿Cuáles son algunos de los aspectos musicales que desarrolla Fray Luis en este poema? El plano sonoro - $-\mathrm{y}$, por lo tanto, el musical - lo genera, en parte, la forma exterior usada por Fray Luis para su oda. Tal es el caso de la "lira", estrofa de cinco versos, introducida en España por Garcilaso, pero empleada por él sólo una vez en la "Canción a la flor del Gnido". Lo ceñido de la forma exterior, en que alternan dos versos endecasílabos con tres heptasílabos, provoca un contraste de gran fuerza rítmica y sonora. No podía ser una forma más adecuada para expresar la grandeza del arte del músico y organista, ceñido a la tierra por la materia corporal, pero deseoso de trascendencia en su conexión con el cosmos o la totalidad musical, fundida a la idea de la divinidad. La oda/canción pareciera concebida para un nuevo Orfeo que toca, no ya la antigua lira mítica, sino un órgano de iglesia. Un Orfeo, por lo tanto, que no desea el descenso a los infiernos porque no ha perdido a ninguna amada. Pero, en verdad, es un Orfeo que aspira al ascenso y a la trascendencia. A través de la música busca la unión con la armonía divina del universo. La primera estrofa nos sumerge de inmediato en un ambiente exterior que inundará de energía sonora y cósmica todo el texto

El aire se serena y viste de hermosura y luz no usada...

Porque la música y la poesía, como hemos visto en las poéticas del Siglo de Oro, son expresiones de nuestra primigenia deidad; a través de ellas nos acercamos a la divinidad de la que nunca fuimos separados

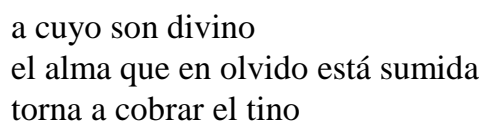

De los pitagóricos arranca la idea de que "el alma es armonía" y que "a consecuencia de cierto castigo, habría sido uncida al yugo del cuerpo" (Alonso, 1971:110-198). También aparece en los textos del Siglo de Oro la idea de que música y poesía son paliativos para purgar el alma y lavarla de la corporal bajeza a que está condenada sobre la tierra. No resulta nada extraño que el culto y sabio profesor de Salamanca hubiera conocido muchos de los textos y poéticas aquí referidas. Las ideas de Pitágoras, pasadas por el tamiz aristotélico, estaban bastante difundidas en los escritos y las poéticas de la época como ha quedado demostrado en los textos disponibles de López Pinciano.

La tercera estrofa de la "Oda a Salinas" inicia el lento alejamiento de lo mundano - un tema reiterativo en Fray Luis - representado por el metal 


\title{
Enrique Valdés
}

noble, símbolo de todo lo terrenal

El oro desconoce

que el vulgo ciego adora

¿Hacia dónde nos quiere llevar el texto? ¿A qué alturas aspira? La cuarta estrofa nos da la clave que dará ulterior sentido a todo el poema

\author{
Traspasa el aire todo \\ hasta llegar a la más alta esfera \\ y oye allí otro modo \\ de no perecedera música...
}

La inversión del mito de Orfeo parece perfecta. El descenso al Hades es ahora ascenso a las esferas celestiales: a la más alta esfera. Es la misma idea que desarrolla Sánchez de Viana al hablar de Platón

...de donde escribe en el Fedro que sólo el alma de los sabios recobra las alas, porque estos se hurtan al cuerpo en la meditación... y a tal levantamiento llaman furor. Ansí que la sabiduría humana es retrato de la divina y la música de nuestros instrumentos figura de la celestial armonía (1986:142).

Resulta sorprendente el paralelismo entre estos textos teóricos y el poema de Fray Luis, que confirma la idea de que el poeta estaba al tanto de los textos publicados en la España de su época. La idea de los siete orbes musicales está expresada en el Compendio apologético en alabanza de la poesía de Bernardo de Balbuena y su desarrollo resulta más amplio que las referencias dispersas en Platón y Aristóteles (1986:274-276). Al parecer, la alta esfera corresponde a los círculos cósmicos o ruedas descritas por la rotación y traslación de los planetas, cuyo movimiento es armonioso y musical. A la música astral, intenta transportarnos la oda, no a través de la misma música, sino a través del silencio o la música del silencio, tan bien lograda en algunos pianísimos —en el lenguaje técnico de hoy— de las grandes sinfonías de Beethoven o de Mahler. Las fieras que Orfeo debe vencer con su voz y el sonido de su "lira" son, en el poema de Fray Luis, las luchas corporales, las cadenas del cuerpo y del tráfico mundano — el oro- que evita la ascensión. Ese "oír de otro modo" representa el triunfo sobre la materia. Es la presencia de Eurídice Aurora- el símbolo de la luz y de la belleza divinas. La estrofa quinta objetada en algunas ediciones - representa la culminación del viaje musical. Ya no es Salinas, el músico, el que toca su instrumento. Es el orden universal decretado por la mano suprema, es decir, la mano misma de Dios, a quien el mismo Fray Luis llama el Gran Maestro 


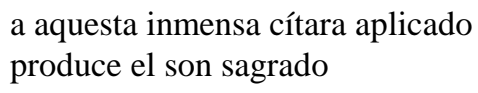

La retribución del viaje de ascenso es la música divina, pero la idea que transciende es que un músico como Salinas, por la pura eficacia de su arte, puede llegar a mirarse como ante un espejo, imitando no sólo la música divina sino a su intérprete sagrado, en perfecta fusión. Pues el mundo, "este templo", está sustentado "por el son sagrado" de la música y la armonía. La concepción cristiana del cielo se hace explícita en la estrofa siete cuando se afirma que

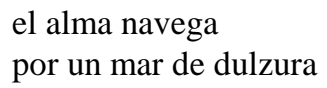

Es el momento de la unión completa entre alma y Dios, del mismo modo como se da en las altas cumbres de la poesía mística de San Juan o de Santa Teresa. El regreso de Orfeo al mundo de las tinieblas corresponde a las últimas tres estrofas del texto de Fray Luis. El poeta que ya ha conocido las profundidades, ahora exhorta a sus amigos a continuar la búsqueda

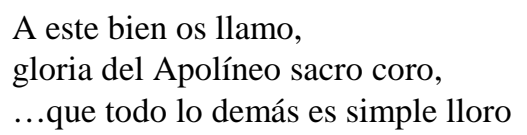

Así como Orfeo pierde su dicha apenas la había alcanzado, el Poeta pierde la alegría de la música divina por estar amarrado a la tumba del cuerpo. La última estrofa evoca una desesperada resignación

Oh, suene de continuo

Salinas, vuestro son en mis oídos

Como en Orfeo, poesía y música son posibilidades de ascenso y de descenso para alcanzar una felicidad siempre fugitiva. Un similar desgarro traspasa la visión de ambas lecturas. La presencia siempre efímera del bien querido, la fugacidad de la dicha. La certeza de la felicidad que se deshace entre las manos por el hechizo de la mirada en Orfeo; por las ataduras corporales en Fray Luis. En ambos poetas hay llanto y tragedia por no lograr en plenitud lo que se vislumbra como alcanzable. Es un dolor que atraviesa sus vidas y que, por ello mismo, justifica la función del arte sobre la tierra.

Santa María 2445*

Osorno (Chile)

evaldes@ulagos.cl 
Enrique Valdés

\section{BIBLIOGRAFÍA}

ADVIS, Luis. Displacer y trascendencia en el arte. Santiago: Universitaria, 1978.

ALONSO, Dámaso. Poesía Española. Ensayo de métodos y límites estilísticos. Madrid: Gredos, 1971.

CABAÑAS, Pablo. El mito de Orfeo en la Literatura Española. Madrid: Consejo Superior de Investigaciones Científicas, 1984.

CURTIUS, E. Robert. Literatura europea y Edad Media latina. México: F. C. E., 1955.

LEÓN, Fray Luis de. Obras completas castellanas de Fray Luis de León. (Ed.) Félix García O. S. A. Madrid: Biblioteca de Autores Cristianos, 1959.

OXFORD UNIVERSITY. The Oxford Annotated Bible. The Holy Bible. Oxford: Oxford University Press, 1962.

PORQUERAS MAYO, Alberto. La teoría poética en el Renacimiento y manierismo españoles. Barcelona: Puvill libros S. A., 1986.

STRAVINSKY, Igor. Poetique musicale. Cambridge Mass. Harvard Univ. Press, 1942. 